\title{
Simulation of anisotropic ice flow and fabric evolution along the GRIP-GISP2 flowline, central Greenland
}

\author{
Olivier Gagliardini, Jagques Meyssonnier \\ Laboratoire de Glaciologie et Géophysique de l'Environnement, CNRS et \\ Universitéfoseph Fourier ( UJF - Grenoble I), 38402 Saint-Martin-d'Hères Cedex, France
}

\begin{abstract}
A model for the anisotropic behaviour of polar ice and the evolution of its strain-induced anisotropy is applied to the flowline between GRIP and GISP2. The linear constitutive law for polycrystalline ice is derived from the uniform-stress model under the assumptions of a linear transversely isotropic behaviour of the ice single crystal and of an orthotropic fabric described by a continuous parameterized orientation-distribution function (ODF). The velocities and fabrics obtained for the observed flowline and bedrock geometry, assuming stationary flow, are compared to those measured at the icesheet surface and down the two boreholes.
\end{abstract}

\section{NOMENGLATURE}

$B \quad$ Bedrock topography

$\bar{B}_{1} \quad$ Fluidity of isotropic ice $\left(\mathrm{MPa}^{-1} \mathrm{a}^{-1}\right)$

c $\quad c$ axis vector

$\bar{b} \quad$ Accumulation rate ( $m$ eq. ice $\mathrm{a}^{-1}$ )

D Strain rate $\left(\mathrm{a}^{-1}\right)$

E Free-surface elevation

$f \quad$ Orientation-distribution function (ODF)

$g \quad$ Acceleration of gravity $\left(\mathrm{m} \mathrm{s}^{-2}\right)$

$\bar{k}_{i} \quad$ ODF strength parameters $(i=1,3)$

$\mathbf{M}_{3} \quad$ Grain-structure tensor

$\overline{\mathbf{M}}_{r} \quad$ Polycrystal structure tensors $(r=1,3)$

$\mathbf{S} \quad$ Deviatoric stress $(\mathrm{MPa})$

$p \quad$ Isotropic pressure $(\mathrm{MPa})$

$Q \quad$ Activation energy $\left(\mathrm{J} \mathrm{mol}^{-1}\right)$

$R \quad$ Gas constant $\left(\mathrm{J} \mathrm{mol}^{-1} \mathrm{~K}^{-1}\right)$

Ro $\quad$ Strength of the fabric

$\{\mathrm{R}\} \quad$ Fixed reference frame

$\left\{{ }^{\mathrm{g}} \mathrm{R}\right\} \quad$ Grain reference frame

$\left\{{ }^{\circ} \mathrm{R}\right\} \quad$ Orthotropy reference frame

$t \quad$ Time (a)

$T \quad$ Temperature $(\mathbf{K})$

$\bar{u}_{i} \quad$ Velocity $\left(\mathrm{ma}^{-1}\right)$

W $\quad \operatorname{Spin}\left(\mathrm{a}^{-1}\right)$

$\mathbf{x} \quad$ Material point $(\mathrm{m})$

$\bar{\alpha}_{r} \quad$ Macroscopic fluidity parameters $(r=1,6)$

$\left(\mathrm{M} \mathrm{Pa}^{-1} \mathrm{a}^{-1}\right)$

$\beta \quad$ Grain anisotropy parameter

$\theta \quad$ Grain $c$ axis co-latitude

$\sigma \quad$ Stress (MPa)

$\varphi \quad$ Grain $c$ axis longitude

${ }^{o} \bar{\varphi} \quad$ ODF angular parameter

$\rho \quad$ Ice density $\left(\mathrm{kg} \mathrm{m}^{-3}\right)$

$\psi \quad$ Grain basal fluidity $\left(\mathrm{M} \mathrm{Pa}^{-1} \mathrm{a}^{-1}\right)$

\section{INTRODUGTION}

Observations on the Greenland Icecore Project (GRIP) and Greenland Ice Sheet Project Two (GISP2) ice cores have shown that polycrystalline ice develops a fabric which is induced by the strain undergone by ice as it descends from the surface to depth in the ice-sheet. At GRIP and GISP2 the fabric evolves from an isotropic fabric at the surface (crystals randomly oriented) to a vertical single-maximum fabric whose strength increases with depth.

Since the ice single crystal is strongly anisotropic, the polycrystalline response depends on the fabric strength and is also anisotropic. As shown by Mangeney and others (1996), when polycrystalline anisotropy is taken into account in a flow model the general trend is an acceleration of flow compared to that of isotropic ice. In this flow model, anisotropy is given as an input and must be extrapolated between a few given data from a limited number of boreholes. However, in order to account for the anisotropy of ice more properly we have to consider the ice fabric as an unknown of the ice-sheet flow problem.

To solve this problem Staroszczyk and Morland (2000) assume that the anisotropy of ice is entirely determined by the accumulated macroscopic deformation. In their model the stress is expressed in terms of the strain rate, of the accumulated strain and of three structure tensors, and all the microprocesses taking place at the grain level are ignored. This model is very efficient, but does not provide results which can be compared to the fabrics observed in ice cores.

In the present paper, a complete solution, i.e. velocity and fabric fields, for the stationary flow of a two-dimensional ice-sheet is presented with an application to the flow of ice between GRIP and GISP2. This solution was obtained by incorporating a micro-macro model for the behaviour of anisotropic polycrystalline ice into a finite-element code for 


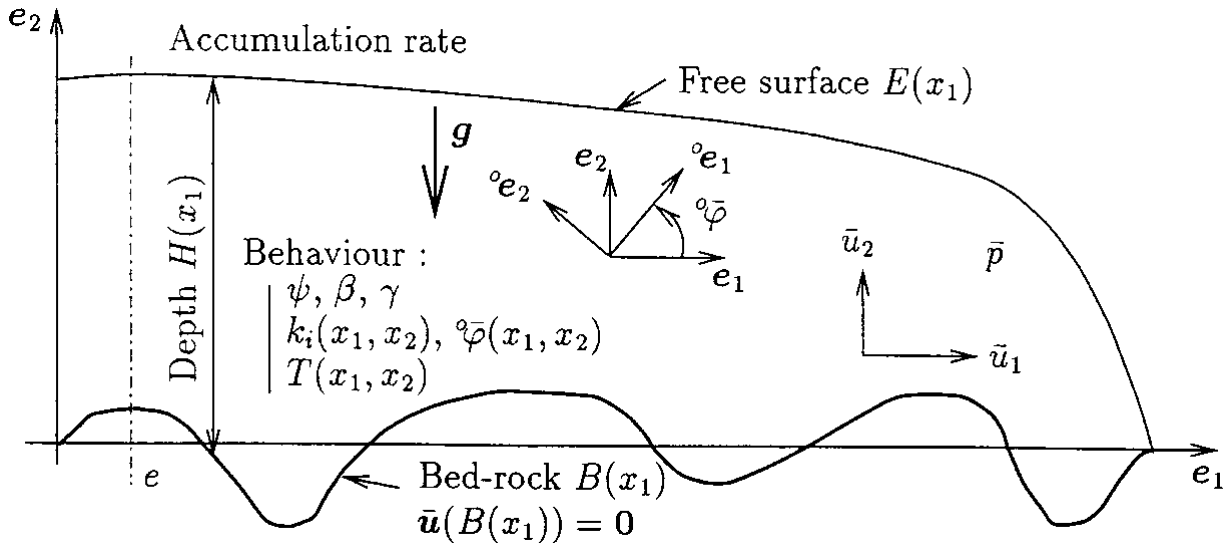

Fig. 1. Definition of the flow problem.

the flow simulation (for more details see Gagliardini, 1999; Gagliardini and Meyssonnier, 1999a; Staroszczyk and Gagliardini, 1999; Gagliardini and Meyssonnier, 1999b). Since the fabric in our model is calculated as an unknown of the flow problem the results can be compared to the fabrics measured in the GRIP and GISP2 cores.

\section{MICRO-MACRO MODEL ASSUMPTIONS}

\section{Notations}

In the following, three Cartesian reference frame are used:

$\{\mathrm{R}\}$ is a fixed reference frame, whose plane $\left(x_{1}, x_{2}\right)$ is the plane of the ice sheet flow, with $x_{1}$ horizontal and $x_{2}$ vertical upwards as shown in Figure 1 .

$\left\{{ }^{\mathrm{o}} \mathrm{R}\right\}$ is the material symmetry reference frame of an orthotropic polycrystal whose axes ${ }^{\circ} x_{i}$ coincide with the orthogonal privileged directions in the polycrystal. Furthermore it is assumed that the plane of symmetry $\left({ }^{\circ} x_{1},{ }^{\circ} x_{2}\right)$ of the polycrystal coincides with the plane $\left(x_{1}, x_{2}\right)$ of ice-sheet flow (i.e. $\left.{ }^{\circ} x_{3}=x_{3}\right)$.

$\left\{{ }^{\mathrm{g}} \mathrm{R}\right\}$ is a local reference frame associated with an individual grain, whose ${ }^{g} x_{3}$ axis coincides with the hexagonal symmetry axis of the grain ( $c$ axis).

Macroscopic quantities associated to a polycrystal or to the ice-sheet are denoted by a super bar symbol. The superscripts "g" and "o" are used to denote any non-scalar quantity expressed in the local reference frame $\left\{{ }^{\mathrm{g}} \mathrm{R}\right\}$ and in the orthotropic symmetry reference frame $\left\{{ }^{\circ} \mathrm{R}\right\}$ respectively. Otherwise, if no superscript is applied, this quantity is expressed in the fixed reference frame $\{R\}$.

\section{Grain behaviour}

Following Meyssonnier and Philip (1996) and Gagliardini and Meyssonnier (1999b) the ice crystal is assumed to behave as a linear transversely isotropic medium. The simplest relation between the strain-rate $\mathbf{D}$ and the deviatoric stress $\mathbf{S}$ is then expressed by

$$
\mathbf{D}=\frac{\psi}{2}\left[\beta \mathbf{S}+(1-\beta)\left(\mathbf{M}_{3} \mathbf{S}+\mathbf{S M}_{3}-2 \operatorname{tr}\left(\mathbf{M}_{3} \mathbf{S}\right) \mathbf{M}_{3}\right)\right]
$$

where $\mathbf{M}_{3}$ is the structure tensor defined by $\mathbf{M}_{3}=\mathbf{c} \otimes \mathbf{c}$ and $\mathbf{c}$ is the grain $c$-axis unit vector $\left({ }^{g} \mathbf{c}=(0,0,1)\right.$ in the local reference frame). The parameter $\psi$ is the fluidity, inverse of viscosity, for shear parallel to the basal plane of the grain, and $\beta$ is the ratio of the shear fluidity in the basal plane to that parallel to the basal plane. $\beta$ is a measure of the grain anisotropy: when $\beta=0$ the grain can deform only by basal glide, as assumed in many models (Lliboutry, 1993; Van der Veen and Whillans, 1994; Mangeney and others, 1997; Gödert and Hutter, 1998), while $\beta=1$ corresponds to an isotropic grain. Since the ice single crystal deforms mainly by shear parallel to its basal plane (Duval and others, 1983), the value of $\beta$ should be significantly less than 1 .

\section{Orthotropic fabric}

Following Meyssonnier and Philip (1996), Staroszczyk and Gagliardini (1999), Gagliardini and Meyssonnier (1999a), the fabric of the ice polycrystal is described by a parameterized orientation-distribution function (ODF) which gives the relative density of grains whose $c$ axes have the orientation $(\theta, \varphi)$ in the global reference frame $\{\mathrm{R}\}$. This parameterized ODF which depends on four parameters is given by

$$
\begin{aligned}
& f\left(\theta, \varphi, \bar{k}_{1}, \bar{k}_{2},{ }^{\circ} \bar{\varphi}\right) \\
& =\left[\sin ^{2} \theta\left(\bar{k}_{1}^{2} \cos ^{2}\left(\varphi-{ }^{\circ} \bar{\varphi}\right)+\bar{k}_{2}^{2} \sin ^{2}\left(\varphi-{ }^{\circ} \bar{\varphi}\right)\right)+\bar{k}_{3}^{2} \cos ^{2} \theta\right]^{-\frac{3}{2}} .
\end{aligned}
$$

The relation

$$
\frac{1}{2 \pi} \int_{0}^{2 \pi} \int_{0}^{\pi / 2} f(\theta, \varphi) \sin \theta \mathrm{d} \theta \mathrm{d} \varphi=1,
$$

which expresses the conservation of the total number of grains, is satisfied for any value of parameters $\bar{k}_{1}, \bar{k}_{2}$ and ${ }^{0} \bar{\varphi}$ under the condition that $\bar{k}_{1} \bar{k}_{2} \bar{k}_{3}=1$. Relation (2) describes an orthotropic fabric with planes of symmetry $\left({ }^{\circ} x_{1},{ }^{\circ} x_{2}\right),\left({ }^{\circ} x_{2},{ }^{\circ} x_{3}\right)$ and $\left({ }^{\circ} x_{3},{ }^{\circ} x_{1}\right)$. In the following, the plane $\left({ }^{\circ} x_{1},{ }^{\circ} x_{2}\right)$ coincides with the plane $\left(x_{1}, x_{2}\right)$ of the ice-sheet flow.

Each parameter $\bar{k}_{i}=\bar{k}_{i}(\mathbf{x})$ gives the strength of concentration of $c$ axes in the direction ${ }^{\circ} \mathbf{e}_{i}$ of the material frame $\left\{{ }^{\mathrm{o}} \mathrm{R}\right\}$ at the material point $\mathbf{x}$ in the ice sheet (a small value of $\bar{k}_{i}$ corresponds to $c$ axes gathered along direction ${ }^{\circ} \mathbf{e}_{i}$; when $\bar{k}_{i}=\bar{k}_{j}$ the plane $\left({ }^{\mathrm{o}} x_{i},{ }^{\mathrm{o}} x_{j}\right)$ is a plane of isotropy). The angle ${ }^{\mathrm{o}} \bar{\varphi}$ defines the rotation of $\left\{{ }^{\mathrm{O}} \mathrm{R}\right\}$ with respect to the global reference frame $\{\mathrm{R}\}$ in the plane $\left(x_{1}, x_{2}\right)$ around the $x_{3}$ axis (see Fig. 1).

\section{Behaviour of orthotropic ice}

Under the assumption of a uniform state of stress in the polycrystal $(\mathbf{S}=\overline{\mathbf{S}})$, the constitutive law corresponding to an orthotropic fabric (Equation (2)) is obtained by expressing 
the macroscopic strain rate as the weighted average of the grains strain-rate given by Equation (1). The resulting relation is

$$
\begin{aligned}
\overline{\mathbf{D}}=<\mathbf{D}>=\sum_{r=1}^{3}[ & \bar{\alpha}_{r} \operatorname{tr}\left({ }^{\circ} \overline{\mathbf{M}}_{r} \overline{\mathbf{S}}\right){ }^{\circ} \overline{\mathbf{M}}_{r}{ }^{\mathrm{D}} \\
& \left.+\bar{\alpha}_{r+3}\left(\overline{\mathbf{S}}^{\mathrm{o}} \overline{\mathbf{M}}_{r}+{ }^{\mathrm{o}} \overline{\mathbf{M}}_{r} \overline{\mathbf{S}}\right)^{\mathrm{D}}\right],
\end{aligned}
$$

where $(.)^{\mathrm{D}}$ denotes the deviatoric part of $($.$) and where the$ weighted average $<$. $>$ of a quantity $x(\theta, \varphi)$ is defined as

$$
<x>=\frac{1}{2 \pi} \int_{0}^{2 \pi} \int_{0}^{\pi / 2} x(\theta, \varphi) f(\theta, \varphi) \sin \theta \mathrm{d} \theta \mathrm{d} \varphi .
$$

The three structure tensors ${ }^{\circ} \overline{\mathbf{M}}_{r}={ }^{\circ} \mathbf{e}_{r} \otimes{ }^{\circ} \mathbf{e}_{r}$, in (4) are defined by the unit vectors ${ }^{\circ} \mathbf{e}_{r}$ of the material reference frame $\left\{{ }^{\circ} \mathrm{R}\right\}$ and the six response coefficients, $\bar{\alpha}_{i}$, are defined in terms of the grain rheological parameters $\psi$ and $\beta$, and of the fabric parameters $\bar{k}_{i}$ and ${ }^{\circ} \bar{\varphi}$ (i.e. $\bar{\alpha}_{i}=\bar{\alpha}_{i}\left(\psi, \beta, \bar{k}_{1}, \bar{k}_{2}, \bar{k}_{3},{ }^{o} \bar{\varphi}\right.$ ) (see Gagliardini and Meyssonnier (1999a) for these relations). For isotropic ice $f(\theta, \varphi)=1, \bar{k}_{1}=\bar{k}_{2}=\bar{k}_{3}=1$, and the macroscopic orthotropic law (4) reduces to a linearly viscous law $\overline{\mathbf{D}}=\bar{B}_{1} \overline{\mathbf{S}} / 2$, where the fluidity $\bar{B}_{1}$ is related to the grain rheological parameters by (Staroszczyk and Gagliardini, 1999; Gagliardini and Meyssonnier, 1999b)

$$
\bar{B}_{1}=\frac{\psi}{5}(3 \beta+2) \text {. }
$$

From (6) it follows that the ratio of the fluidity, $\psi$, for shear parallel to the grain basal plane to the fluidity $\bar{B}_{1}$ of isotropic ice reaches its maximum value of 2.5 when the grain behaviour is the most anisotropic (i.e. when $\beta=0$ ). This value is lower than the experimental value of 10 obtained by Pimienta and others (1987), therefore the influence of anisotropy on ice-sheet flow, as given by the present model, is under-estimated. The fluidity $\bar{B}_{1}$ (and also $\psi$ according to Equation (6)) is related to temperature by the Arrhenius law

$$
\bar{B}_{1}(T)=\bar{B}_{1}\left(T_{0}\right) \mathbf{e}^{\frac{Q}{R}\left(\frac{1}{T_{0}}-\frac{1}{T}\right)},
$$

where $Q$ is the activation energy, $R$ is the gas constant and $T$ and $T_{0}$ are temperatures in Kelvin.

\section{FLOW PROBLEM}

\section{Equations and boundary conditions}

The micro-macro model for the constitutive law of orthotropic ice was incorporated in a finite-element code in order to solve the gravity-driven, stationary, plane flow of an icesheet with fixed surface elevation and bedrock topography. Since the surface elevation is fixed, the accumulation rate must be considered as a variable determined by the solution of the flow problem. The flow problem to be solved and the notation used in this section are summarized in Figure 1.

The quasi-static stress-equilibrium equations corresponding to plane strain flow expressed in the fixed reference frame $\{\mathrm{R}\}$ are

$$
\begin{aligned}
& \frac{\partial \bar{S}_{11}}{\partial x_{1}}+\frac{\partial \bar{S}_{12}}{\partial x_{2}}+\frac{\partial \bar{p}}{\partial x_{1}}=0, \\
& \frac{\partial \bar{S}_{12}}{\partial x_{1}}+\frac{\partial \bar{S}_{22}}{\partial x_{2}}+\frac{\partial \bar{p}}{\partial x_{2}}=\rho g
\end{aligned}
$$

where $\bar{p}=\operatorname{tr}(\bar{\sigma}) / 3$ is the isotropic pressure and $\rho g$ is the density of ice times the acceleration of gravity. If ice density is assumed to be a constant then mass conservation reduces to the incompressibility equation

$$
\frac{\partial \bar{u}_{1}}{\partial x_{1}}+\frac{\partial \bar{u}_{2}}{\partial x_{2}}=0
$$

where $\bar{u}_{i}$ is the velocity component in direction $\mathbf{e}_{i}$.

Since fabric evolution is supposed to be due solely to grain-lattice rotation (recrystallization is not accounted for), the steady-state condition $\partial(f \sin \theta) / \partial t=0$ at each point $\mathbf{x}$ in the ice sheet implies that the net flux of grains entering or leaving the interval $(\mathrm{d} \theta, \mathrm{d} \varphi)$ at point $\mathbf{x}$ (either by grain transport along the flow streamline or by change of orientation of the grain due to lattice rotation) is zero, that is

$$
\frac{\partial f \sin \theta}{\partial x_{i}} \bar{u}_{i}+\frac{\partial \dot{\theta} f \sin \theta}{\partial \theta}+\frac{\partial \dot{\varphi} f \sin \theta}{\partial \varphi}=0
$$

The grain rotation rates $\dot{\theta}$ and $\dot{\varphi}$ in (10) are determined from the decomposition of the spin of each grain into a component due to its viscoplastic deformation (measured in the grain reference frame) and a component corresponding to the rotation of the basal planes (Meyssonnier and Philip, 1996). According to Gagliardini (1999) and Gagliardini and Meyssonnier (1999b), under the assumption that the spin of the grain, $\mathbf{W}$, expressed in the global referenceframe $\{\mathrm{R}\}$ is equal to the macroscopic spin of the polycrystal $\overline{\mathbf{W}}$ (Taylor-type assumption) the grain rotation-rates $\dot{\theta}=\dot{\theta}\left(x_{i}\right)$ and $\dot{\varphi}=\dot{\varphi}\left(x_{i}\right)$ corresponding to plane flow can be expressed in terms of the deviatoric stress components $\bar{S}_{11}\left(x_{i}\right), \bar{S}_{22}\left(x_{i}\right)$, $\bar{S}_{12}\left(x_{i}\right)$ and of the macroscopic spin $\bar{W}_{12}\left(x_{i}\right)$ as

$\dot{\theta}=-\frac{\psi}{8} \sin 2 \theta$

$$
\left[3\left(\bar{S}_{11}+\bar{S}_{22}\right)+\left(\bar{S}_{11}-\bar{S}_{22}\right) \cos 2 \varphi+2 \bar{S}_{12} \sin 2 \varphi\right]
$$

$\dot{\varphi}=\frac{\psi}{4}\left[\left(\bar{S}_{11}-\bar{S}_{22}\right) \sin 2 \varphi-2 \bar{S}_{12} \cos 2 \varphi\right]-\bar{W}_{12}$.

Equations (10) and (11) completely describe the evolution of the ice fabric in the particular case of a plane flow.

The stress on the ice-sheet free surface denoted by $E=E\left(x_{1}\right)$ is such that

$$
\bar{\sigma} . \mathbf{n}_{\mathrm{s}}=\bar{\sigma}^{0} \overline{\mathbf{n}}_{\mathrm{s}}
$$

where $\mathbf{n}_{\mathrm{s}}=\left(\partial E / \partial x_{1},-1\right)$ is the outward unit normal to the surface and $\bar{\sigma}^{0}$ is the atmospheric pressure. Since the surface is assumed to be stationary, the velocity components $\bar{u}_{i}^{s}=$ $\bar{u}_{i}\left(x_{1}, E\right)$ and the vertical accumulation rate $\bar{b}=\bar{b}\left(x_{1}\right)$ satisfy the kinematic condition

$$
\bar{u}_{1}^{s} \frac{\partial E}{\partial x_{1}}-\bar{u}_{2}^{s}=\bar{b} .
$$

The ice deposited on the ice-sheet surface is assumed to be isotropic, therefore the fabric parameters $\bar{k}_{i}$ have the fixed value

$$
\bar{k}_{i}\left(x_{1}, E\right)=1 \quad i=1,2,3 .
$$

No sliding is assumed at the ice--bedrock interface $B=B\left(x_{1}\right)$, hence

$$
\bar{u}_{i}\left(x_{1}, B\right)=0 \quad i=1,2,
$$

and the vertical axis of symmetry of the (plane) ice sheet is assumed to be at $x_{1}=e$ (see Fig. 1) which implies

$$
\bar{u}_{1}\left(e, x_{2}\right)=0, \quad \text { and } \quad \bar{S}_{12}\left(e, x_{2}\right)=0 .
$$

\section{Numerical methods}

Using the orthotropic viscous law (4) for the behaviour of polycrystalline ice and with boundary conditions (12), (15), 
(16), the stress-equilibrium equation (8) and the incompressibility equation (9), are solved by the finite-element method. The isotropic pressure is used as a Lagrange multiplier in order to solve the incompressibility equation. The elements are six-node triangles with a linear interpolation of the pressure and a quadratic interpolation of the velocities and fabric parameters $\bar{k}_{1}, \bar{k}_{2}$ and ${ }^{\circ} \bar{\varphi}$.

The ODF parameters corresponding to stationary flow are obtained by solving the grain-conservation equation (10) along the streamlines computed from the finite-element solution for the velocities. The ODF parameters at each node $M$ of the finite-element mesh are computed in two successive stages as follows:

the streamline passing through $M$ is computed from $M$ to the ice-sheet surface by solving the set of equations $\mathrm{d} x_{i} / \mathrm{d} t=-\bar{u}_{i}$ (upstream procedure). During this phase $\bar{S}_{11}, \bar{S}_{22}, \bar{S}_{12}$ and the rotation rate $\bar{W}_{12}$ are calculated at each fictitious time-step $\mathrm{d} t$ (corresponding to an increment of displacement along the streamline) by using the finite-element solution for the velocity and the constitutive law (4), then stored.

the evolution of the ODF parameters along the streamline is calculated from the surface where ice is assumed to be isotropic (14). By assuming that the directions of the principal stresses do not change significantly during $\mathrm{d} t$, the parameters $\bar{k}_{i}$ are shown (see Gagliardini, 1999) to be the solution of

$$
\begin{aligned}
& \mathrm{d} \bar{k}_{1} / \bar{k}_{1}=(\psi / 4)\left(\bar{S}_{11}+\bar{S}_{22}+\bar{S}\right) \mathrm{d} t, \\
& \mathrm{~d} \bar{k}_{2} / \bar{k}_{2}=(\psi / 4)\left(\bar{S}_{11}+\bar{S}_{22}-\bar{S}\right) \mathrm{d} t,
\end{aligned}
$$

where $\bar{S}^{2}=\left(\bar{S}_{11}-\bar{S}_{22}\right)^{2}+4 \bar{S}_{12}^{2}$. During $\mathrm{d} t$, the change of orientation of the material symmetry reference frame $\left\{{ }^{\mathrm{o}} \mathrm{R}\right\}$, i.e. $\mathrm{d}^{\mathrm{O}} \bar{\varphi}$, is taken as the weighted average of the rotation $\dot{\varphi} \mathrm{d} t$ of the grains given by (11). These equations are solved using the Runge-Kutta method.

The velocity and fabric fields corresponding to stationary flow are calculated by solving iteratively the velocity problem for a given fabric field, then the fabric problem for a given velocity field, until convergence is achieved (i.e. when the norm of the relative deviation of each variable

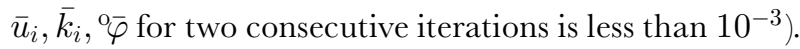

\section{APPLICATION TO THE GRIP-GISP2 FLOWLINE}

Following Schøtt and others (1992) and Hvidberg and others (1997), our model is applied to the flowline from GRIP to GISP2. The two boreholes GRIP (3238 m a.s.l.; Dansgaard and others, 1993) and GISP2 (3215 ma.s.l.) are located in central Greenland, at $3 \mathrm{~km}$ and $27 \mathrm{~km}$ to the west of the actual summit of Greenland, respectively. Both boreholes have been drilled down to bedrock and their depths are $3029 \mathrm{~m}$ and $3053 \mathrm{~m}$, respectively (Gow and others, 1997) (see Fig. 2). Many measurements have been made in this area and some of them are used as inputs to the model whereas others are used for model assessment.

\section{Model inputs}

The numerical values assigned to the basic parameters are given in Table 1. The other assumptions are as follow:

The flow is plane strain and the two-dimensional flow domain presents a symmetry axis located at the actual

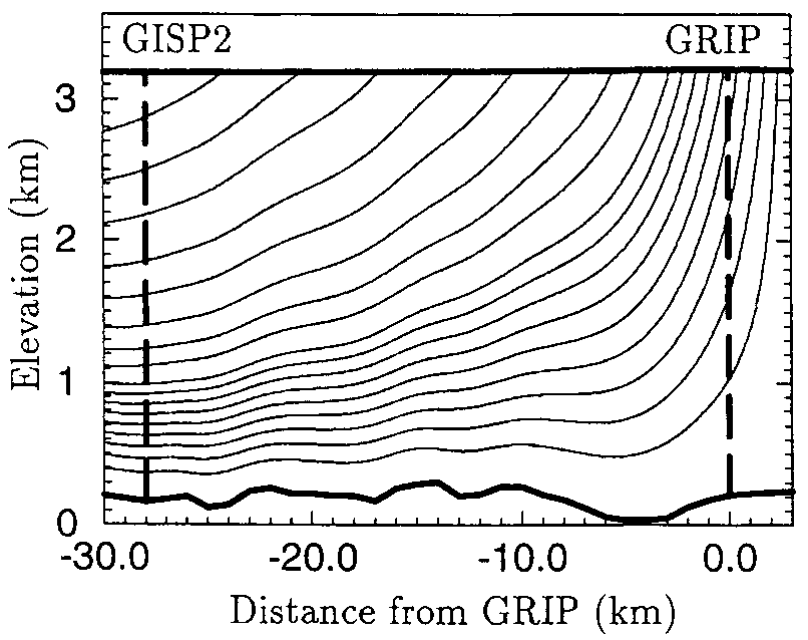

Fig. 2. Surface and bedrock topographies, GRIP and GISP2 borehole locations and computed streamlines.

Table 1. Value of the parameters used for finite-element computation

$\beta=0.25$

$\rho=917 \mathrm{~kg} \mathrm{~m}^{-3}$

Grain anisotropy parameter in Equation (1)

$Q=78000 \mathrm{~J} \mathrm{~mol}^{-1}$

Ice density

$R=8.314 \mathrm{~J} \mathrm{~mol}^{-1} \mathrm{~K}^{-1}$

Activation energy

Gas constant

summit of Greenland at $x_{1}=e=3 \mathrm{~km}$. Its length is $184 \mathrm{~km}$ and it ends with a vertical free surface which should not influence flow in the vicinity of the two boreholes since it is located more than 50 ice thicknesses downstream from GISP2. The finite-element mesh contains 7351 nodes.

The flow is assumed to be stationary (in order to calculate a consistent field of fabrics) and the surface elevation is fixed according to field measurements (Hodge and others, 1990; see Fig. 2).

The bedrock topography conforms to that measured by Hodge and others (1990) taking into account the measurements of Hempel and Thyssen (1993) and Jacobel and Hodge (1995). For $x_{1}<-40 \mathrm{~km}$ the bedrock is assumed to be flat (see Fig. 2).

The grain anisotropy parameter, $\beta$, is given the value $\beta=0.25$ and the fluidity, $\psi$, is determined in terms of the fluidity of isotropic ice $\bar{B}_{1}$ according to (6). $\bar{B}_{1}$ is calculated by imposing an age of 14450 years at $1753.4 \mathrm{~m}$ depth in the GRIP ice core (Johnsen and others, 1992).

The temperature field is derived from the profile measured in the GRIP borehole (Gundestrup and others, 1993) by assuming the temperature to be independent of the $x_{1}$ coordinate and dependent on the reduced depth (ratio of depth to ice thickness). This assumption is justified since the temperature profiles at GRIP and GISP2 are very similar. The temperature increases from $-31.7^{\circ} \mathrm{C}$ at the surface to $-8.4^{\circ} \mathrm{C}$ at the bedrock.

The fabric corresponding to stationary state is calculated only in the domain $-38 \leq x_{1} \leq 3 \mathrm{~km}$ and is extrapolated downstream (down to $x_{1}=-181 \mathrm{~km}$ ) with the vertical profile of fabric obtained at $x_{1}=-38 \mathrm{~km}$. 


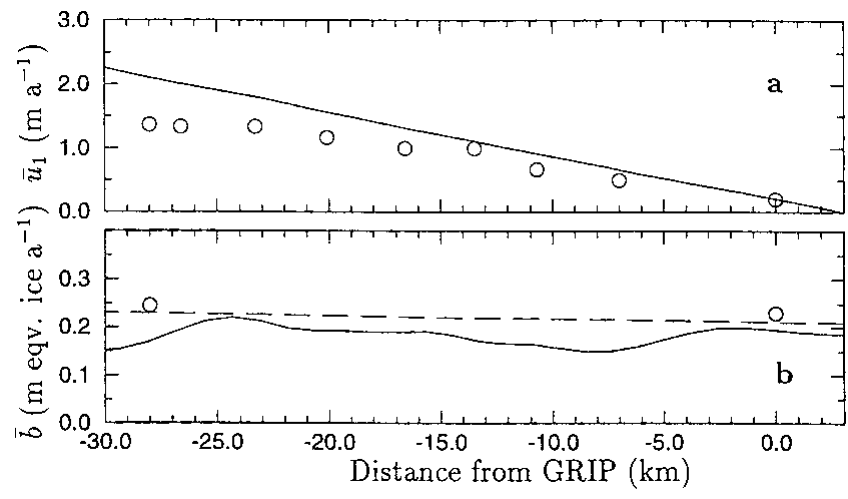

Fig. 3. (a) Horizontal velocity $\bar{u}_{1}$ and ( $b$ ) accumulation rate $\bar{b}$ on the surface. The circles show the horizontal velocities measured by Waddington and others (1995) and Keller and others (1995) and the accumulation rate from Dahl-fensen and others (1993) and Meese and others (1994).

\section{Results}

As can be inferred from Equations (10) and (11), the fabric at a given point of the flow domain does not depend on the value of the fluidity of isotropic ice $\bar{B}_{1}$ (nor on $\psi$ ), which is consistent with the assumption of stationary flow. On the other hand $\bar{B}_{1}$ acts as a scaling parameter for the velocities. By prescribing an age of 14450 years at $1753.4 \mathrm{~m}$ depth for the ice of the GRIP core (Johnsen and others, 1992), the value of $\bar{B}_{1}$ at $-10^{\circ} \mathrm{C}$ is found to be $\bar{B}_{1}\left(-10^{\circ} \mathrm{C}\right)=0.09 \mathrm{MPa}^{-1} \mathrm{a}^{-1}$. This value is lower than that inferred by Lipenkov and others (1997) from bubble closure measurements $\bar{B}_{1}\left(-10^{\circ} \mathrm{C}\right)$ $=0.16 \pm 0.07 \mathrm{MPa}^{-1} \mathrm{a}^{-1}$, but is still realistic.

As shown in Figure 3, the computed horizontal velocities are larger than those measured by Waddington and others (1995) and Keller and others (1995). Conversely the calculated accumulation rates are lower than those measured by Dahl-Jensen and others (1993) and Meese and others (1994). Nevertheless, the horizontal velocities and accumulation rates obtained with the model are relatively close to the measurements.

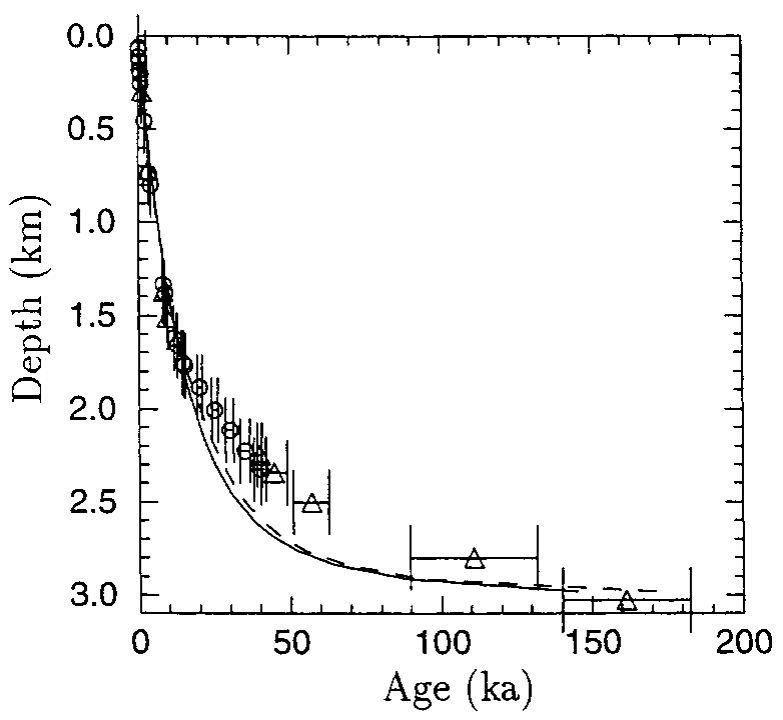

Fig. 4. Evolution of the age of the ice vs depth in the GRIP (solid line) and GISP2 (dashed line) ice cores. Fohnsen and others' (1992) dating in GRIP is represented by circles, Meese and others' (1997) dating in GISP2 by triangles.
Figure 4 shows the ice-dating curves in GRIP and GISP2 calculated by the model compared to those measured by Johnsen and others (1992) and Meese and others (1997). Since the value of $\bar{B}_{1}$ was obtained by prescribing the age of the ice at $1753.4 \mathrm{~m}$ in the GRIP ice core the dated points are very well fitted by the computed curve from the surface down to this depth. For greater depths, and for both boreholes, the ages predicted by the model are younger than those measured. In the GISP2 borehole, the age is younger down to $2800 \mathrm{~m}$, even though the no-sliding condition implies an infinite age at the bedrock contact. In Figure 4 a change in the curvature of the measured age vs depth curve at the Holocene-Wisconsin transition at $1650 \mathrm{~m}$ can be observed. This change is not reproduced by our model since the ice behaviour, the fabric and the temperature are evolving in a continuous manner with depth.

Fabric evolution in the GRIP ice core, represented by using Thorsteinsson and others' (1997) statistical parameter $R o$, as well as the orientation ${ }^{\circ} \bar{\varphi}$ of the material symmetry reference frame are shown in Figure 5. Ro characterizes the strength of the fabric and is defined as

$$
R o=2\|<\mathbf{c}>\|-1,
$$

where $\mathbf{c}$ is the $c$ axis unit vector expressed in the global reference frame $\{\mathrm{R}\},<$. $>$ is the weighted average defined by Equation (5) and $\|$.$\| is the norm of a vector. Ro is equal to 0$ for a random fabric and takes the maximum value of 1 when all the crystals have the same orientation. Using Ro induces a loss of information on the fabric compared to the ODF description since the ODF (Equation (2)) contains three parameters to characterize the form and strength of the fabric. Nevertheless, since the strengths of measured fabric are given in terms of Ro (Thorsteinsson and others, 1997) our results are presented under this form to allow comparison. As shown in Figure 5a the strengths Ro obtained with the
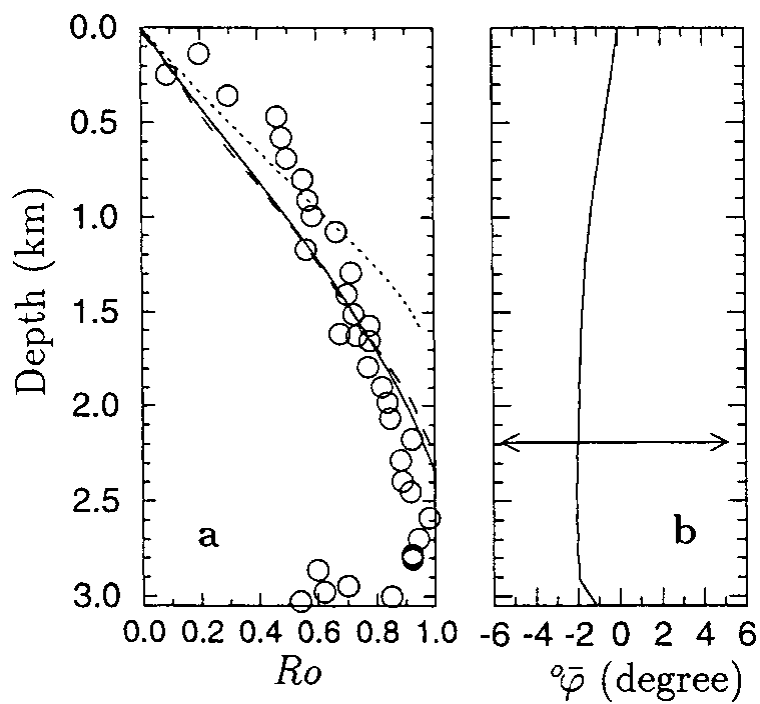

Fig. 5. (a) Fabric strength parameter Ro in the GRIP ice core ( solid line) and in the GISP2 ice core (dashed line). Data from Thorsteinsson and others (1997) in the GRIP ice core are shown by circles. The dotted line shows fabric evolution obtained with the model by using the ice strain-rate history derived from DahlJensen and others' (1993) model. (b) Orientation ${ }^{\circ} \bar{\varphi}$ of the orthotropy reference frame a function of depth in the GRIP ice core (solid line). Data from Thorsteinsson and others (1997) in the GRIP ice core are shown by the arrows. 
model reproduce very well the measurements from $1000 \mathrm{~m}$ down to $2800 \mathrm{~m}$. Above $1000 \mathrm{~m}$ the calculated values of $R o$ are lower than those measured, i.e. the model predicts a slower increase of the fabric. Below $2800 \mathrm{~m}$ fabrics induced by dynamic recrystallization are not reproduced by the model which does not take this mechanism into account. Figure $5 \mathrm{~b}$ shows that the deviation from the vertical of the ${ }^{\circ} x_{2}$ axis of the material symmetry reference frame is less than $2^{\circ}$ in the GRIP ice core. According to Thorsteinsson and others (1997) the average of the $c$ axis directions does not deviate more than $10^{\circ}$ from the axis of the ice core, and is usually within $1^{\circ}-6^{\circ}$ from the core axis. Therefore the computed maximum value of $2^{\circ}$ is compatible with the observations.

\section{Discussion}

Apart from its direct interest for ice-sheet-flow modelling, the comparison of the modelled fabrics to observation shows clearly the influence of flow conditions on fabric evolution. By using the Dansgaard-Johnsen flow model (Dansgaard and Johnsen, 1969) to provide a strain-rate history input to micro-macro models for anisotropic behaviour and fabric evolution, Castelnau and others' (1996) viscoplastic-selfconsistent model as well as the present uniform-stress model (Gagliardini and Meyssonnier, 1999b) are found to predict a rate of fabric evolution greater than that observed below $650 \mathrm{~m}$ in the GRIP ice-core (see Fig. 5a). The DansgaardJohnsen one-dimensional flow model (Dansgaard and Johnsen, 1969) is based on the following assumptions: (a) the ice deforms under uniaxial compression with a constant vertical strain rate from the surface down to $1750 \mathrm{~m}$ (Dahl-Jensen and others, 1993), then the strain rate decreases linearly with depth down to zero on the bedrock; (b) the present accumulation rate of $0.23 \mathrm{~m}$ ice eqv. $\mathrm{a}^{-1}$ is the mean accumulation rate during the Holocene; and (c) the surface and the bedrock are horizontal and with a constant ice thickness of $3028 \mathrm{~m}$. In the present study the age of the ice was prescribed at a fixed depth and since the streamlines obtained with this two-dimensional flow model are not vertical the strain rates experienced by the ice are lower than those given by Dansgaard and Johnsen's (1969) model. As a consequence, the accumulated strain at a given depth, and then the rate of fabric concentration vs depth, calculated by our model in the GRIP borehole are smaller than those given by Dansgaard and Johnsen's (1969) model. Figure 6 shows the evolution of the strain rates $\bar{D}_{11}, \bar{D}_{22}$ and $\bar{D}_{12}$ given by our flow model in the GRIP borehole (these are not the actual strain rates undergone by the ice in the ice core since the streamlines are not vertical).

As regards the assumed linear behaviour of polar ice, this assumption is justified at least for the upper part of ice sheets where the deviatoric stresses are very low (Pimienta and others, 1987; Lipenkov and others, 1997), however an extension of the model to non-linear behaviour is possible without theoretical difficulty when using the uniform-stress homogenization method (Lliboutry, 1993).

\section{CONGLUSION}

A model for the linear mechanical behaviour of anisotropic polar ice and for the evolution of ice anisotropy has been coupled with a finite-element model to simulate the stationary flow of a two-dimensional ice sheet.

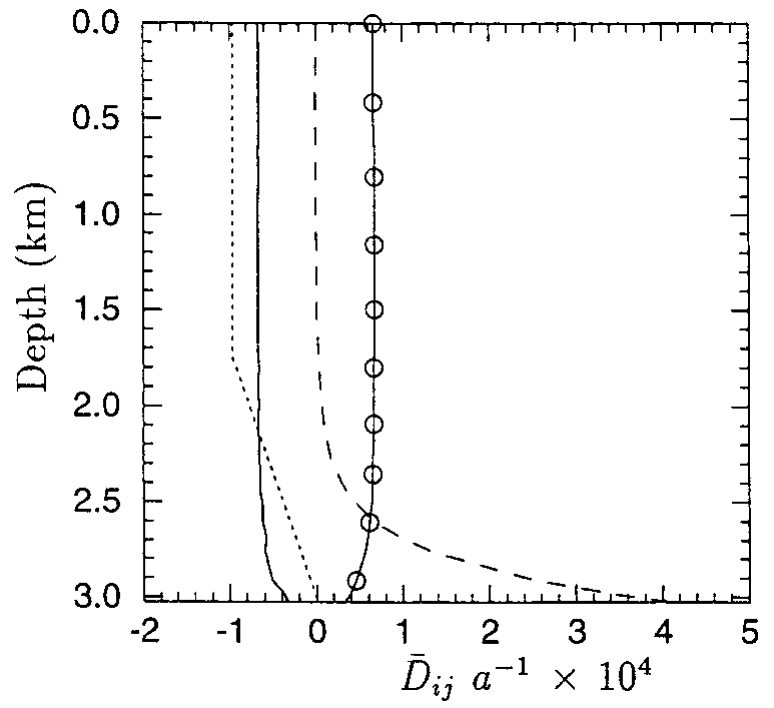

Fig. 6. Evolution of strain rates in the GRIP ice core as a function of depth: $\bar{D}_{22}$ (solid line), $\bar{D}_{11}$ (solid line and circle) and $\bar{D}_{12}$ (dotted line). The dashed line shows the evolution of the strain rate $\bar{D}_{22}$ assumed in the Dahl-fensen and others' (1993) model.

The basic ingredients of the micro-macro model are the description of the ice fabric by a continuous orientation distribution function (ODF) which gives the density of grains with a given $c$ axis orientation, and Reuss' assumption of a uniform stress in the ice polycrystal which allows us to derive the mechanical properties of ice by homogenization, using the ODF as a weighting function. The ODF evolution is described by an equation of continuity, assuming that no recrystallization occurs.

The field of fabrics in the ice-sheet domain is described using a quadratic interpolation of the ODF parameters assigned to each node of the finite-element mesh. The finiteelement solution of the flow problem for a given field of fabrics, obtained in terms of velocities, allows us to compute the trajectory of any material point of the flow domain as well as the strain history undergone by ice along this line. With the assumption of stationary flow, the knowledge of the strainhistory along a streamline allows us to compute the corresponding fabrics. These two basic steps are repeated until convergence is achieved.

An application of the model to the flow between the GRIP and GISP2 drilling sites has been presented. The results of the model are in reasonable agreement with field data as regards the horizontal surface velocities, the magnitude of the accumulation rate and the strength of the fabrics measured along the GRIP core. They show that the flow conditions strongly influence fabric development.

\section{AGKNOWLEDGEMENTS}

This work was supported by the Commission of European Communities under contract ENV4-CT95-0125 "Fabric Development and Rheology of Polar Anisotropic Ice for Ice Sheet Flow Modelling”. O. Gagliardini was granted a BDI-scholarship by the Centre National de la Recherche Scientifique (Département SPI): this financial support is gratefully acknowledged. The Laboratoire de Glaciologie et Géophysique de l'Environnement is associated with the Université Joseph Fourier-Grenoble I. 


\section{REFERENCES}

Castelnau, O., Th. Thorsteinsson, J. Kipfstuhl, P. Duval and G. R. Canova. 1996. Modelling fabric development along the GRIP ice core, central Greenland. Ann. Glaciol., 23, 194-201.

Dahl-Jensen, D., S. J. Johnsen, C. U. Hammer, H. B. Clausen and J. Jouzel. 1993. Past accumulation rates derived from observed annual layers in the GRIP ice core from Summit, central Greenland. In Peltier, W. R., ed. Ice in the climate system. Berlin, etc., Springer-Verlag, 517-532. (NATO ASI Series I: Global Environmental Change 12.)

Dansgaard, W. and S. J. Johnsen. 1969. A flow model and a time scale for the ice core from Camp Century, Greenland. F. Glaciol., 8(53), 215-223.

Dansgaard, W. and 10 others. 1993. Evidence for general instability of past climate from a 250-kyr ice-core record. Nature, 364(6434), 218-220.

Duval, P., M. F. Ashby and I. Anderman. 1983. Rate-controlling processes in the creep of polycrystalline ice. 7. Phys. Chem., 87(21), 4066-4074.

Gagliardini, O. 1999. Simulation numérique d'un écoulement bidimensionnel de glace polaire présentant une anisotropie induite évolutive. (Ph.D. thesis, Université Joseph Fourier-Grenoble I.)

Gagliardini, O. and J. Meyssonnier. 1999a. Plane flow of an ice sheet exhibiting strain-induced anisotropy. In Hutter, K., Y. Wang and H. Beer, eds. Advances in cold-region thermal engineering and sciences: technological, environmental, and climatological impact. Berlin, etc., Springer-Verlag, 171-182. (Lecture Notes in Physics 533.

Gagliardini, O. and J. Meyssonnier. 1999b. Analytical derivations for the behaviour and fabric evolution of a linear orthotropic ice polycrystal. 7. Geophys. Res., 104(B8), 17,797-17,809.

Gödert, G. and K. Hutter. 1998. Induced anisotropy in large ice shields: theory and its homogenization. Continuum Mech. Thermodyn., 10(5), 293-318.

Gow, A. J. and 6 others. 1997. Physical and structural properties of the Greenland Ice Sheet Project 2 ice cores: a review. f. Geophys. Res., 102(C12), 26,559-26,575.

Gundestrup, N., D. Dahl-Jensen, S. J. Johnsen and A. Rossi. 1993. Bore-hole survey at dome GRIP 1991. Cold Reg. Sci. Technol., 21 (4), 399-402.

Hempel, L. and F. Thyssen. 1993. Deep radio echo soundings in the vicinity of GRIP and GISP2 drill sites, Greenland. Polarforschung, 62(1), 1992, 11-16.

Hodge, S. M., D. L. Wright, J. A. Bradley, R.W. Jacobel, N. Skou and B. Vaughn. 1990. Determination of the surface and bed topography in central Greenland. 7. Glaciol., 36(122), 17-30.

Hvidberg, C. S., D. Dahl-Jensen and E. D. Waddington. 1997. Ice flow between the GRIP and GISP2 boreholes in central Greenland. 7. Geophys. Res., 102 $(\mathrm{Cl} 2), 26,851-26,859$.

Jacobel, R.W. and S. M. Hodge. 1995. Radar internal layers from the
Greenland summit. Geophys. Res. Lett., 22 (5), 587-590.

Johnsen, S. J. and 9 others. 1992. Irregular glacial interstadials recorded in a new Greenland ice core. Nature, 359(6393), 311-313.

Keller, K., N. Gundestrup, D. Dahl-Jensen, C. C. Tscherning, R. Forsberg and S. Ekholm. 1995. The ice deformation and mass balance at the summit of Greenland as determined by GPS and gravity measurements. Gronlands Geol. Undersogelse, Open File 95-5, 15-18.

Lipenkov, V.Ya., A. N. Salamatin and P. Duval. 1997. Bubbly-ice densification in ice sheets: II. Applications. f. Glaciol., 43(145), 397-407.

Lliboutry, L. 1993. Anisotropic, transversely isotropic nonlinear viscosity of rock ice and rheological parameters inferred from homogenization. Int. 7. Plasticity, 9(5), 619-632.

Mangeney, A., F. Califano and O. Castelnau. 1996. Isothermal flow of an anisotropic ice sheet in the vicinity of an ice divide. 7. Geophys. Res., 101 (B12), 28,189-28,204.

Mangeney, A., F. Califano and K. Hutter. 1997. A numerical study of anisotropic, low Reynolds number, free surface flow for ice sheet modeling. $\mathcal{F}$. Geophys. Res., 102(B10), 22,749-22,764.

Meese, D. A. and 8 others. 1997. The Greenland Ice Sheet Project 2 depth-age scale: methods and results. F. Geophys. Res., 102(C12), 26,411-26,423.

Meese, D. A. and 8 others. 1994. The accumulation record from the GISP2 core as an indicator of climate change throughout the Holocene. Science, 266 (5191), 1680-1682.

Meyssonnier, J. and A. Philip. 1996. A model for the tangent viscous behaviour of anisotropic polar ice. Ann. Glaciol., 23, 253-261.

Pimienta, P., P. Duval and V. Ya. Lipenkov. 1987. Mechanical behavior of anisotropic polar ice. International Association of Hydrological Sciences Publication 170 (Symposium at Vancouver 1987 - The Physical Basis of Ice Sheet Modelling), 57-66.

Schøtt, C., E. D. Waddington and C. F. Raymond. 1992. Predicted timescales for GISP2 and GRIP boreholes at Summit, Greenland. F. Glaciol., 38 (128), 162-168.

Staroszczyk, R. and O. Gagliardini. 1999. Two orthotropic models for strain-induced anisotropy of polar ice. f. Glaciol., 45(151), 485-494.

Staroszczyk, R. and L.W. Morland. 2000. Plane ice-sheet flow with evolving orthotropic fabric. Ann. Glaciol., $\mathbf{3 0}$ (see paper in this volume).

Thorsteinsson, Th., J. Kipfstuhl and H. Miller. 1997. Textures and fabrics in the GRIP ice core. F. Geophys. Res., 102(C12), 26,583-26,600.

Van der Veen, C. J. and I. M. Whillans. 1994. Development of fabric in ice. Cold Reg. Sci. Technol., 22(2), 171-195.

Waddington, E. and 16 others. 1995. The role of glacier geophysics in the GISP2 ice core program. Arct. Res. U.S., 9(Fall/Winter), 10-19. 